
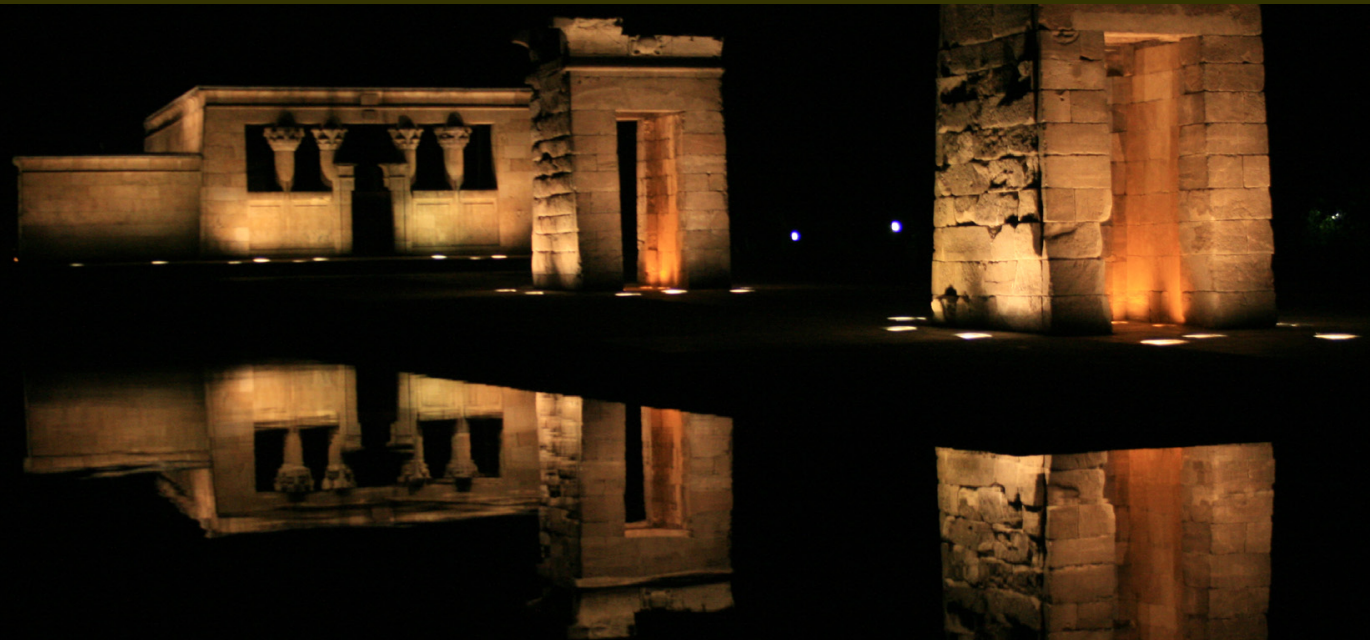

\title{
Editor:
}

Jaime Almansa Sánchez

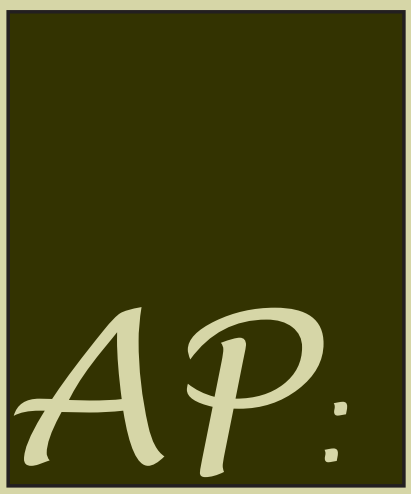

www.arqueologiapublica.es

Ontine Journat in Public Archaeology 


\title{
REVIEWS
}

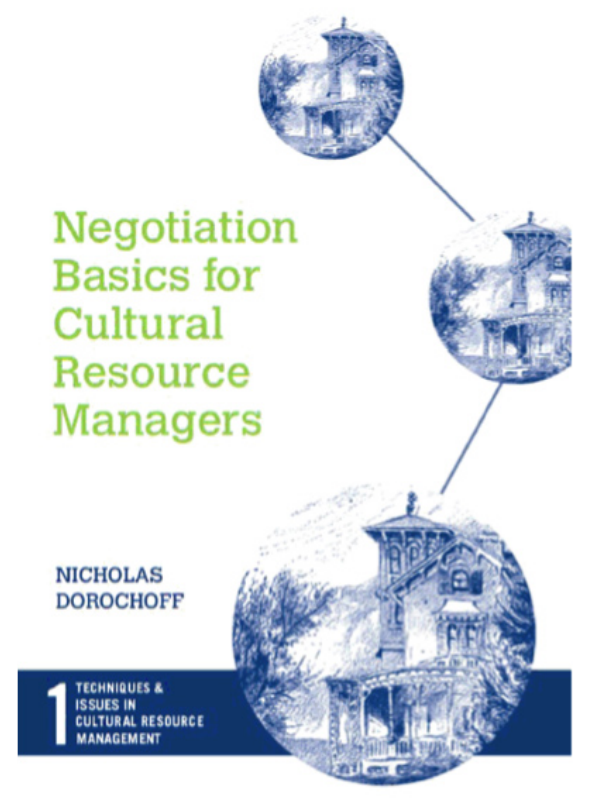

Alicia TORIJA Archaeologist

\section{Negotiation Basics for Cultural Resource Management [Nicholas Dorochoff]}

\author{
Left Coast Press \\ ISBN: 978-1-59874-095-0 \\ 133 pages
}

\begin{abstract}
"Conflict is the gadfly of thought. It stirs us to observation and memory. It instigates invention. It shocks us out of sheep-like passivity, and sets us at noting and contriving... conflict is a sine qua non of reflection and ingenuity."

John Dewey (1922)
\end{abstract}

\section{Summary:}

Anyone in the cultural resource management world will tell you that much of the job is successfully negotiating consensus on a course of action between various stakeholders. Brief, practical, and geared specifically for cultural resource managers, consultants, and other interested parties, the author slices the negotiation process into its various component parts and steps. In a workshop fashion, Dorochoff takes the reader through the negotiation process, showing where conflicts can arise, how they can be solved, and how a clear understanding of negotiation strategies can lead to successful resolutions. (back cover) 
As Nicholas Dorochoff himself suggests in the introduction to his book Negotiation Basics for Cultural Resource Managers, archaeologists and preservationists are fatally uninformed and uninterested in negotiation. Dorochoff, who has a long corporate background, did not get involved in preservation until his forties. This background is not only manifest in the style and content of his short work; it is the very reason why he wrote it in the first place. It became clear to him, he argues, that preservationists tend to take "an 'us-versus-them' approach and [...] they would rather not engage at all rather than attempt to work together with those whose values differed from their own." (p. 7) The result of this approach is much more harmful than helpful to their goals, and prevents them from saving countless sites that could be saved with even elementary knowledge or interest in negotiation. The aim of his project then, is to rectify this situation. The book is a summary of relevant business negotiation basics aimed specifically at preservationists, attempting to introduce the latter to the tactics and procedures that would allow them to argue their cases in business terms. Since negotiation is a large part of preservation, this book fills an important niche that - in spite of this work - remains largely untouched.

In his approach to negotiation, Dorochoff places heavy emphasis on preparation, organisation and communication. He separates the procedure into five clearly defined stages, the first of which, what he calls investigation and preparation, takes place before any actual discussion begins (second stage). The remaining three phases of connection, interaction, and integration occur once the first two stages have been accomplished, and the talks begin. He also identifies six "negotiation contexts" most commonly encountered by resource managers, which he organises as well into a neat grid based on the level of formality and the need for agreement: Number of parties, Communication method, Communication mode, Need for agreement, Nature of the resolution, Negotiation type. Public hearings, consultations and contracts are all very formal contexts for negotiation, but have an increasing need for agreement, with contracts being the most demanding of all. Unstructured and persuasive writing tend to be rather informal, but while the latter requires little to no agreement the former generally does. The bulk of the monograph (i.e., chapters three to seven) is taken up by examining chapter to chapter each negotiation stage in detail, and assessing how they apply individually to each of the six negotiation contexts listed above. The chapters are introduced with definitions, and include real examples of negotiations in preservation and cultural resource management. 
Just as each chapter begins by defining the stage it is outlining, the second chapter introduces the chapters to come with a definition. "Negotiation is communication that allows two or more parties with differing goals to arrive at a resolution" (p. 16). The author comes back to this description nearly in every chapter, often more than once. If Dorochoff's need for definition and order is not obvious to the reader at this stage, it becomes clear as the book progresses. Each stage has its unique purpose and structure, often involving a model or a number of distinct points to be addressed. In chapter three, for example, which focuses on identifying the goals and motivations of all negotiating parties, Dorochoff lists three motivation types: There are those motivated by power who are generally uninterested in maintaining relationships or making concessions; those who are motivated by achievement and will thus be willing to make enough concessions, at least as far as this will allow them to move their goals forward; and those who are motivated by affiliation and are most interested in maintaining networks and connections, therefore making the most concessions. He also returns to these variations often in the chapters that follow.

Reading between the lines, Dorochoff clearly gives the impression of taking negotiation very seriously and giving much importance to formalities. He not only suggests that it is unwise to stray from the procedure or the considerations he lists, but also asserts that it is necessary to adhere to them completely. In chapter six, he introduces a "problem solving cycle", which illustrates the circular path a negotiation usually follows. In black and white he lists that during communication both parties should review the situation, reconsider their goals, refine their positions, present and discuss them, and begin the cycle again, ad infinitum, until an agreement is reached. In chapter eight, which discusses roadblocks, he asserts his view that every time a negotiation breaks down, one of the steps in this problem solving cycle is neglected. Usually, he argues, negotiation breakdown is the result of a failure of communication. If it is the result of an "output problem," that is "one of the parties is either incapable of adjusting their position or simply refuses to do so" (p. 102), new goals and concessions must be brought to the table or one of the parties has to walk away. For Dorochoff, it seems to be as simple as that.

The author presents a very organized and easy to follow guide to negotiating preservation and resource management. The book reads very much like a textbook, and is indeed intended to be read as such. No prior knowledge of the subject is required from the reader, and the 
rigidly defined formula for negotiation presented can be taken as a guideline for beginners. Many of the points may seem rudimentary seems obvious to say that the way in which information is presented is crucial for success - and many indeed are, but considering the stages and the steps involved in them does encourage one to take negotiation more seriously. In this way, Dorochoff does achieve his goal. In presenting the basics of the negotiation procedure, to which many of his intended audience's negotiation counterparts adhere, especially those somewhat allergic to the business aspect of communication, he gives them the opportunity to communicate on their terms.

Dorochoff's work is, overall, a good resource for beginners in cultural resource management. However, its rigidly outlined method and sometimes obvious advice may not appeal to more seasoned preservationists. Many might enjoy the same benefit from reading an article-length version of the monograph and find many of the expanded explanations unnecessary. For such readers, however, the organization and headings of the book make reading through the main points easy and painless. The extensive bibliography is also a useful resource, no matter the reader's experience. Just as well organized as the main body of the book, the bibliography gives a wide range of sources in cultural resource management, various aspects of business communication and the negotiation process, as well as strategies and tactics that preservationists will find useful. In this way, Negotiation Basics can be useful to experienced and inexperienced negotiators alike, and, all in all, achieves its goals well.

Nevertheless, the text is missing an explanation of why culture needs different negotiating strategies. As recorded in his text, Kiram points out: "The behaviors that negotiators from a culture characteristically use to enact a negotiation strategy are related to other features of that culture including its values and norms. The following features of culture seem to be related to the variability in negotiation strategy across cultures: Individualism Vs Collectivism; Egalitarianism Vs Hierarchy; Low-Context Vs High-Context Communications". (Kiram, 2005) In that sense, the work of Salacuse (1998) is very telling, the author asked 310 people to participate in a survey asking them to rate their trading style analyzing ten factors of the process. Its aim was to assess the effects of their origin (8 different occupations, and 12 countries) on its strategy when starting a negotiation. "Various cultures differed on the interpretation of what constitutes a deal. To some, the deal is the contract that will be relied upon when new situations should arise. 
Other culture groups view the contract as an instrument that outlines general principles versus detailed rules" (Horst, 2007, 25) Although it may be considered that the sample in the experiment is small, it can be concluded that each actor in a negotiation process leading to their own frames of reference are those of culture, character, interests, gender, etc. The study demonstrates that in some culture the negotiating process is meant only as a battle to win, while others include a priori rule that combines losing and winning as the process route.

Although some of the examples in the text refer to heritage, this issue is not theorized. The question of the development of cultural heritage is part of the conflicts that contemporary trends of globalization generate. Globalization holds within it aspects of homogenization and cultural heterogeneity. It is in the context of these conflicts, the national and local identities in which cultural creation and development of the cultural heritage of the people turns out to be a key factor. The strength of 'the outside', driven by globalization, can lead to an underestimation of the national (or the local, or the group) for the benefit of the global (or rather, of the hegemonic forces in cultural production at an international level).

"Heritage conflicts that can arise out of land possession, structure extensions, services, infrastructure, inhabitation, non-compliance to the regulations/municipal byelaws" (Nitin, 2007) But that list can be added such controversial issues as inheritance claim subtracted by governments at war, claims on human remains found in archaeological sites and deposited in museums, shipwrecks, etc., repeated anywhere in the world.

"The disputing party can be individuals, group of inhabitants or the community inhabiting the heritage buildings. Even as the civil cases get sorted out as per the due process, the parties apparently become more hostile to the structure. An historic building, which is a matter of pride, is now seen as a cause of the ongoing problems. This situation becomes more volatile over time and the community tends to neglect the historic building and loses concern". (Nitin, 2007) There are many ways to approach the conflict, some may argue that it is aware of the laws and it is not easy to understand the guidelines imposed on heritage management. Others understand that their rights have been violated. In any case we do not speak of a single law or a single scenario, so the conflicts are not easy to solve and the figure of mediation and expert existence is so necessary. The scope of conflict resolution is wide. 
We should not forget that, in addition to negotiating, there are other methods of conflict resolution well-studied in the abundant literature son las referencias de la bibliografía: (Cohen 1997, Moore and Woodrow 2004) but absent from the book:

-Early Neutral Evaluation is a process by which a non-binding, reasoned evaluation is given to the parties, based on the merits of the case, from an experienced, neutral third party.

-Arbitration is a private determination of the controversial issue by a neutral party, who can make a binding award. When arbitration is combined with another type of alternative dispute resolution process, such as conciliation and mediation, it is termed Hybrid Arbitration. -Consultation is the process of seeking, discussing, and considering the views of others, and, where feasible, seeking agreement with them on how historic properties should be identified, considered, and managed.

A challenging reality awaits archaeologists and other heritage workers in the new century, in which openness, dialogue and negotiation (understood as influence, persuasion, compromise, and learning, both as a process and as a structure) will probably be our best methodological tools. However, no negotiation is possible if the archaeologist is unable to make a self-criticism of his own position and discourse (as a specialist), which is crucial to try to understand the public's relationship with the past and, eventually, develop solutions tailored to that public.

The conflict resolution techniques are more often than not used after a dispute has arisen. However, anticipation of future forms of conflict would be very important for conflict resolution, taking into account that there are also productive conflicts which are characterized by the sharing of mutually beneficial ideas, acceptance of multilateral sources of information, an array of solutions, integrative negotiations, etc.

Finally, it is obvious that good practices and ethics favor negotiation and that the only road to a succesful negotiation is persistence, despite the obstacles that stand in the way.

\section{References}

Cohen, Raymond, Negotiating Across Cultures. Washington, D.C.: United States Institute of Peace, (1997) 
Paul R. Horst, Jr : Cross-cultural negotiations (2007)

Kiran Kumar, K. : The Culture and Negotiation Strategies (2005) http://www.indianmba.com/Faculty_Column/FC178/fc178.html

Moore, Chris and Woodrow, Peter: "Mapping Cultures - Strategies for Effective Intercultural Negotiations" (March 2004)

Nitin Sinha, R.: Conflict resolution in heritage management http://www.heritagechambers.org/

Salacuse Jeswald W. "Ten Ways the Culture Affects Negotiating Style: Some Survey Results." Negotiation Journal 14, no. 3 (July 1998): 221-240

http://dorochoffconsulting.com/

http://www.wipo.int/amc/en/center/specific-sectors/art/icom/ 


\section{AP: Ontine Journat in Public Archaeology}

\section{Editor:}

Jaime Almansa Sánchez

Email: almansasanchez@gmail.com

Assistant editor:

Elena Papagiannopoulou

Edited by:

JAS Arqueología S.L.U.

Website: www.jasarqueologia.es

Email: jasarqueologia@gmail.com

Address: Plaza de Mondariz, 6, 28029 - Madrid (Spain)

--

Cover Image: Noche en el templo de Debod (J. Almansa)

Copyright (C) 2013 JAS Arqueología S.L.U. (edition) \& Authors (content)

ISSN: $2171-6315$

Quotation:

Torija, A. 2013. Review: Negotiation Basics for Cultural Resource Management. AP Journal Vol. 3, 148-154.

AP Journal is a peer-reviewed journal devoted exclusively to Public Archaeology. It is freely distributed online on the Website:

www.arqueologiapublica.es

You can also follow us on:

Blogger:

= http://arqueologiapublica.blogspot.com/

Twitter:

http://twitter.com/APjournal

Facebook:

http://www.facebook.com/APJournal 